\title{
Clinical course and prognosis of musculoskeletal pain in patients referred for physiotherapy: does pain site matter?
}

\author{
Nils-Bo de Vos Andersen ${ }^{1}$, Peter Kent ${ }^{2,3}$, Jakob Hjort ${ }^{4}$ and David Høyrup Christiansen ${ }^{5^{*}}$
}

\begin{abstract}
Background: Danish patients with musculoskeletal disorders are commonly referred for primary care physiotherapy treatment but little is known about their general health status, pain diagnoses, clinical course and prognosis. The objectives of this study were to 1) describe the clinical course of patients with musculoskeletal disorders referred to physiotherapy, 2) identify predictors associated with a satisfactory outcome, and 3) determine the influence of the primary pain site diagnosis relative to those predictors.

Methods: This was a prospective cohort study of patients $(n=2,706)$ newly referred because of musculoskeletal pain to 30 physiotherapy practices from January 2012 to May 2012. Data were collected via a web-based questionnaire 1-2 days prior to the first physiotherapy consultation and at 6 weeks, 3 and 6 months, from clinical records (including primary musculoskeletal symptom diagnosis based on the ICPC-2 classification system), and from national registry data. The main outcome was the Patient Acceptable Symptom State. Potential predictors were analysed using backwards step-wise selection during longitudinal Generalised Estimating Equation regression modelling. To assess the influence of pain site on these associations, primary pain site diagnosis was added to the model.
\end{abstract}

Results: Of the patients included, 66\% were female and the mean age was 48 (SD 15). The percentage of patients reporting their symptoms as acceptable was 32\% at 6 weeks, $43 \%$ at 3 months and 52\% at 6 months. A higher probability of satisfactory outcome was associated with place of residence, being retired, no compensation claim, less frequent pain, shorter duration of pain, lower levels of disability and fear avoidance, better mental health and being a non-smoker. Primary pain site diagnosis had little influence on these associations, and was not predictive of a satisfactory outcome.

Conclusion: Only half of the patients rated their symptoms as acceptable at 6 months. Although satisfactory outcome was difficult to predict at an individual patient level, there were a number of prognostic factors that were associated with this outcome. These factors should be considered when developing generic prediction tools to assess the probability of satisfactory outcome in musculoskeletal physiotherapy patients, because the site of pain did not affect that prognostic association.

Keywords: Musculoskeletal pain, Physiotherapy, Cohort study, Prognosis

\footnotetext{
* Correspondence: david.christiansen@vest.rm.dk

${ }^{5}$ Department of Occupational Medicine, Regional Hospital West Jutland-

University Research Clinic, Herning, Denmark

Full list of author information is available at the end of the article
} 


\section{Background}

Musculoskeletal disorders are a common cause of illhealth, with substantial personal, community and societal consequences [1, 2]. In Denmark, over $50 \%$ of the adult population will have experienced pain or discomfort within the last 14 days, and 37\% report that they have been severely bothered by their pain [3]. Musculoskeletal pain is one of the most common reasons that people seek medical help in primary care, with up to $30 \%$ having at least one contact with their general practitioner due to musculoskeletal pain conditions over a period of 18 months [4]. In Denmark, patients with musculoskeletal pain are often referred for physiotherapy treatment [5], but the general health status, distribution of pain diagnoses and clinical course in these patients has not been described.

Identifying prognostic factors and subgroups of patients who respond best to physiotherapy interventions is considered an important research priority [6, 7]. Therefore, in the last two decades a large number of studies have identified potential predictors of outcomes in different musculoskeletal pain conditions [8-12]. Predictive factors can vary depending on differences in study populations, settings, statistical procedures and outcome measures [13].

Commonly used outcome measures in musculoskeletal pain prognostic studies have been improvement in pain, improvement in function or various definitions of 'disabling pain', but there are reasons why outcome measures that tap into broader aspects of recovery might be suitable alternative measures of outcome. The first reason is that the relationship between pain and function is strongly influenced by psychosocial attributes, such as coping, catastrophisation, pain beliefs and pain selfefficacy [14]. Secondly, because of the fluctuating clinical course of much musculoskeletal pain, the relatively low likelihood of complete recovery, and the high recurrence rate [15], contemporary treatment includes a focus on promoting active coping strategies despite pain and on restoring functional activity [16], and therefore outcome measures ideally would tap into these constructs. Therefore, outcome measures that assess the acceptability of a symptom state not only assess patients' adaption to their health condition but also are not restricted to a single dimension of their condition.

The Patient Acceptable Symptom State (PASS) is measured using a question that assesses the level of symptoms beyond which patients consider themselves well and, while it was originally developed for patients with rheumatic disorders $[17,18]$, it may also be appropriate for more broad use in musculoskeletal pain conditions. To our knowledge, the PASS has not been previously applied as an indicator of a satisfactory outcome in patients with diverse musculoskeletal disorders referred to primary care physiotherapy and the predictors associated with this outcome have not been previously evaluated in this context.

In addition, most prognostic factor research in musculoskeletal pain has been centred on people with pain in specific anatomical pain sites (e.g. low back pain, neck pain or shoulder pain) [8-10]. However, there is a view that some prognostic factors are likely to be similar, regardless of the specific pain site. For example, a recent systematic review that compared primary care prognostic factors across different anatomical pain sites, found that despite considerable heterogeneity between studies, some factors consistently emerged across different regional pain complaints [19]. As clinicians in primary care often treat a variety of musculoskeletal pain patients, such knowledge is useful. These findings also suggest that, as different regional pain syndromes share similar prognostic attributes, in musculoskeletal pain these may be more prognostic than the primary pain site diagnosis itself [6].

Therefore, the three objectives of the study were to: 1 ) describe the clinical management and course of Danish patients referred to physiotherapy due to musculoskeletal pain, on the outcomes of pain intensity, disability (activity limitation), sick leave and whether they perceived their symptoms as acceptable at follow-up (satisfactory outcome), 2) identify predictors associated with satisfactory outcome, and 3) investigate the influence of primary pain site diagnosis on the strength of those associations.

\section{Methods}

\section{Study design and population}

This was a prospective cohort study conducted in primarycare physiotherapy practices in Denmark. Denmark is divided into five geographical regions, with each region administering its own public hospitals and primary health care services, including physiotherapy practices. A total of 30 physiotherapy practices in four regions (Capital Region of Denmark, Region of Southern Denmark, Central Denmark Region, Northern Denmark Region) participated in the study. Each physiotherapist was requested to collect completed questionnaires and clinical data on newly referred patients with musculoskeletal disorders in the period from January 2012 to May 2012. Consecutive patients were invited to participate if they fulfilled the following inclusion criteria: aged 18 years or above, able to understand Danish well enough to self-complete the questionnaires, not referred for home treatment, and not having received physiotherapy treatment for the same problem in the preceding 3 months. All participants signed written informed consent forms and the study was approved by the Danish Data Protection Agency (No. 2007-58-0010). As treatment was not affected by 
participation in the study, under Danish law, this study did not need ethics approval (Act on Research Ethics Review of Health Research Projects, October 2013) [20].

\section{Data collection}

Questionnaire and clinical data were collected using an existing web-based clinical database (www.fysdb.dk). Patients who agreed to participate in the study were asked to complete on-line questionnaires 1-2 days prior to the first physiotherapy consultation (baseline) and at 6 weeks, 3 and 6 months follow up. Participants were notified by e-mail when the follow-up questionnaires were available for completion. The questionnaires included items about education, weight, height, smoking, and physical activity, as previously used in other Danish population-based surveys [3]. Pain, disability, pain behavior, sleep and mental health were measured by the following validated questionnaires: Standard Evaluation Questionnaire (SEQ) [21-23], the Örebro Musculoskeletal Pain Screening Questionnaire (MSPQ) [24, 25] and the Mental Health Scale - Five (MH-5) [26].

As patients who are referred to physiotherapy have diverse musculoskeletal disorders, we used a multidimensional assessment tool (SEQ) that was not specific to only one body region. The SEQ assesses pain, disability, and sleep disturbance in three separate modules: SEQpain [21], SEQ-disability [22] and SEQ-sleep [23]. In contrast to most other musculoskeletal pain assessment tools, it can be used with pain in the upper limbs, lower limbs or spinal regions. As a Danish language version of the SEQ was not available, as part of this study, the SEQ modules were forward and back translated, crossculturally adapted and its measurement properties evaluated using internationally recommended methods [2729]. Test-retest reliability of the Danish version of the SEQ was deemed to be acceptable and construct validity was described relative to validated region-specific scales [30-34], with the results being similar to those in the original language version [21, 23]. (See Additional file 1 for more detail). Lastly, information on health-related income support, physiotherapy interventions received and number of consultations was obtained by the Danish National Register on Public Transfer Payments [35] and the National Health Service Register [36],

\section{Prognostic factors}

\section{Primary pain site diagnosis}

At the initial physiotherapy consultation, the patients' primary musculoskeletal pain site diagnosis was recorded using the International Classification for Primary Care $2^{\text {nd }}$ edition (ICPC-2) system [37], which is reliable and valid for classifying musculoskeletal disorders [38]. Prior to the start of the study, all participating physiotherapists were invited to attend a 4-h workshop to standardise the method of data collection. Additional descriptions of the data collection procedures were made available to clinicians via the on-line clinical registry software.

\section{Potential prognostic variables}

Based on previous literature $[8,19,39]$, the following candidate prognostic factors from four health domains were included:

1) Sociodemographic factors which included sex, age, educational level (categorised into unskilled, lower level ( $<3$ years), vocational and training, medium level (3-4 years), higher level ( $>4$ years), and other), geographical region (i.e. the physiotherapy practice's location in one of four regions), information on health-related income support received (classified into none (no record of transfer payments), temporary (sickness benefit, vocational rehabilitation benefit, or cash benefit, except if due to unemployment), permanent (disability pension, or voluntary early retirement that may be due to health reasons), flex-job (which is an income subsidised job due to limited work capacity) or age retirement). These definitions have been used to quantify social and economic consequences of health-related disability in other prospective cohort studies [40, 41]. Furthermore, information on private health insurance, any ongoing compensation claim (litigation) for their current pain condition, or previous claim was obtained;

2) Pain and Function were measured by the SEQ pain and disability modules, which included (i) items on duration of pain ( $<1$ month, $1-3$ months, $4-12$ months and $>12$ months), frequency of pain (constant, daily basis, 2-6 days a week, 1-4 times a month and less often) and pain medication (several times a day, once a day, 2-6 days a week, 1-4 times a month, rarely, and never), pain location and number of pain sites (shown on a pain chart), pain intensity in body regions scored on a numerical rating scale $(0=$ no pain, $10=$ intolerable pain), (ii) a subscale of pain during activity consisting of 12 items $(0=$ no pain, $10=$ intolerable pain), and (iii) a subscale of disability consisting of 12 items $(0=$ no difficulties, $10=$ not possible to perform) covering activities of daily living in three sections, namely, the upper, lower and spinal body regions, that were converted into a sum score $0-100$, where 0 represented no pain/no difficulties;

3) Psychological factors included (i) three questions on fear of physical activity in leisure and work activities, each scored on a 0 to 10 numeric scale $(0=$ completely agree, $10=$ completely disagree) and added to become a sum score (0-30), (ii) one 
question on ability to cope and deal with pain $(0=$ no possibility, 10 = completely) from the MSPQ [24, 42], (iii) the SEQ sleep module, which contained two questions on sleep problems and influence of sleep problems in daytime activity scored on a 0 to 10 numeric scale $(0=$ no problems, $10=$ severe problems) converted into a sum score 0-100 [23], and (iv) five questions on well-being scored on a 5point Likert scale from the MH-5 [26] converted into a score $0-100(0=$ worst possible state); and

4) Health behaviour, including being a smoker, Body Mass Index calculated from self-reported height and weight, and days per week being physical active $>30$ min scored on an 8-point scale ranging from 0 $=$ none to $7=$ every day.

\section{Outcome}

The main outcome was the Patient Acceptable Symptom State (PASS) measured by a single-item question adapted from the original question designed for rheumatology patients $[17,18]$, that has also been found useful as an outcome measure for patients with knee and hip osteoarthritis [43]. The wording of the question was 'Taking into account the many ways your pain affects your daily life, if you were to remain for the next few months as you are now, would you consider your current state to be satisfactory" The question was answered by selecting either the 'yes' or 'no' box. The capacity for the PASS to define the highest level of symptom at which patients find their condition acceptable [44] has been shown to be stable over time [45] and across different patient-reported outcome domains (i.e. pain, function and global assessment) [43].

\section{Data analysis}

Descriptive statistics (percentages, means) were used to report the clinical course. We calculated the number of missing values, follow-up response rates, and differences in baseline characteristics between responders and nonresponders at each time point and across administrative regions. For each time point, pain and disability scores, the percentages of patients being on temporary health-related benefits, and the proportion of participants who perceived their symptoms as acceptable (PASS), were calculated and change over time was analysed by longitudinal linear mixed models for continuous variables and Generalised Estimating Equation (GEE) models for categorical variables [46].

Analysis of predictors for satisfactory outcomes was performed by multivariable regression modelling (GEE). Consideration of the number of variables to include in multivariable model building was based on the rule-ofthumb that a least 10 cases per variable were needed to avoid over-fitting the model [47, 48]. Initially, candidate variables were checked for their univariate association with the outcome and for possible collinearity. Where variables were highly correlated $(>0.7)$, only one of the variables was retained. For continuous variables, the logodds linearity assumption was checked; in case of nonlinearity, the variable was recoded as a categorical variable. Next, a stepwise backward regression analysis was performed. At each step, the variable with the highest $p$ value was removed from the model until all remaining variables had a p-value below 0.05 . Then the variable primary symptom diagnosis (ICPC-2 classification) was added to the model and the models were compared. To explore if the significance level would affect the inclusion of variables, sensitivity analysis was performed by repeating the stepwise backward regression analysis using a p-value below 0.2 to retain variables. In addition, the possible influence of further sub-grouping symptom diagnosis was explored by reclassifying neck and low back patients into those with or without radiating pain. All statistical analyses were performed using Stata Version 13 (StataCorp LP, College Station, TX, USA).

\section{Results \\ Baseline characteristics}

The flow of participants within the study is shown in Fig. 1. A total of 4,885 patients who were referred to physiotherapy matched the inclusion criteria and 2,706 (55\%) consented to participate in the study. Their baseline characteristics are presented in Table 1. Missing values did not exceed $3 \%$ for any baseline variable. Patients who failed to complete any follow-up questionnaires were more often men than women, unskilled or with lower educational level, using pain medication, smokers, having more co-morbidity, less physically active and having higher pain, disability and psychological scores $(p<0.05)$.

\section{Primary symptom diagnosis and treatment}

The distribution of the primary pain site diagnosis (ICPC-2 classification) is presented in Fig. 2. Low back pain was the most prevalent classification, followed by neck pain and shoulder pain. The 197 physiotherapists treated a median of 18 patients (IQR 13 to 23) each. The median number of treatments was 6 (IQR 3 to 10). Over the whole group, the prevalence of physiotherapy treatments used was exercise therapy 36\%, manual therapy $36 \%$, instruction/advice on home exercise $22 \%$ and the use of other physical modalities (e.g. electrotherapy and thermotherapy) $6 \%$. At an individual patient level, the treatment recorded over the course of treatment, included exercise therapy at least once for $83 \%$ of patients and, when combining exercise therapy and/or instruction/advice on home exercises, the prevalence was $95 \%$.

\section{Clinical course}

On average, patient improvement at the 6-month follow-up was 2.9 (95\% Confidence interval CI 2.7 to 


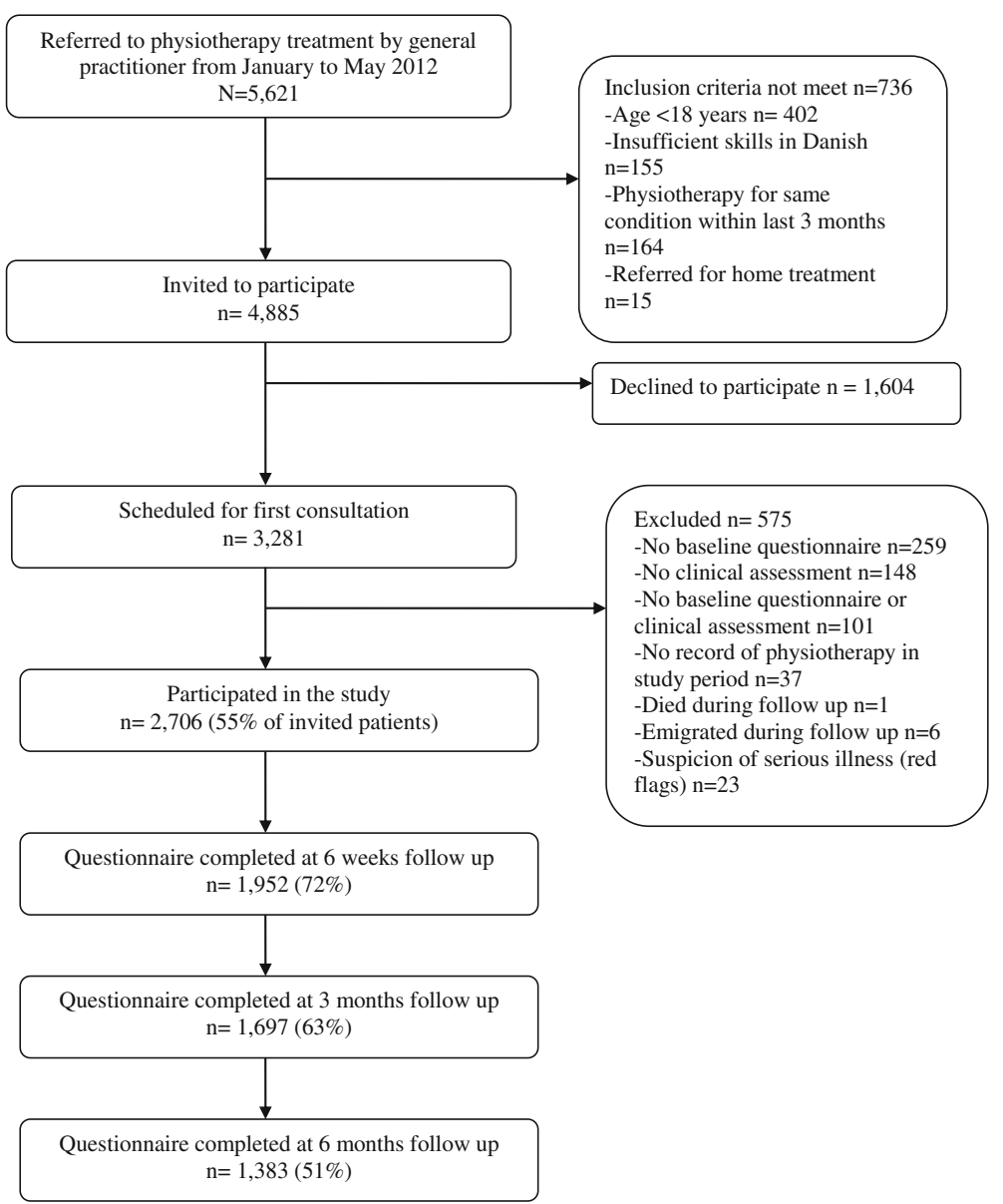

Fig. 1 Flow of participants through the study

3.0) on their pain intensity scores and 9.7 (95\% CI 8.9 to 10.5) on their disability scores. The prevalence of being on temporary health-related benefits was reduced from $12 \%$ at baseline to $8 \%$ at the 6 -month follow up - a total reduction of $4.1 \%$ (95\% CI $3.0 \%$ to $5.3 \%$ ) - when excluding patients who retired or received permanent healthrelated income support. The percentages of patients perceiving their symptoms as acceptable increased from $32 \%$ at 6 weeks to $43 \%$ at 3 months and $52 \%$ at 6 months - an estimated difference of $19.1 \%$ (95\% CI $16.3 \%$ to 21.7\%) On average, patients who perceived their symptoms as acceptable had significantly better pain and disability scores at the three follow up time points than those patients who did not perceive their symptoms as acceptable, mean difference 1.8 (95\% CI 1.7 to 2.0 ) for pain intensity and 7.2 (95\% CI 6.4 to 8.0$)$ for disability.

\section{Predictors of satisfactory outcome}

Table 2 shows the results of the final multivariable model, with and without the primary musculoskeletal pain diagnosis variable. Nine predictors were identified: geographic region, health-related income support, compensation claim, duration of pain, frequency of pain, disability level, fear avoidance beliefs, mental health and smoking; with the outcome variable being patients who perceived their symptoms as acceptable during the course of the 6-month follow up. Adding the primary symptom diagnosis to that model had little impact on these associations, as no single pain diagnosis was predictive of a satisfactory outcome. For the selection of variables, changing the significance level to 0.2 added two additional predictors (gender and sleep problems), but with minimal impact on other associations. Similarly, sub-grouping patients with neck and low back pain into those with radiating and non-radiating pain did not affect the results.

\section{Discussion}

This study evaluated the clinical course, treatment, prevalence of satisfactory outcome, and predictors of satisfactory outcome in musculoskeletal physiotherapy patients, including the possible influence of a primary pain site diagnosis on those predictors. Over the 6-month follow-up period, statistically significant and clinically 
Table 1 Baseline characteristics $(n=2,706)$

\begin{tabular}{|c|c|c|}
\hline \multicolumn{3}{|l|}{ Socio-demographic } \\
\hline \multicolumn{3}{|l|}{ Geographical Regions, n (\%) } \\
\hline Capital Region of Denmark & 594 & $(22.0)$ \\
\hline Region of Southern Denmark & 735 & $(27.2)$ \\
\hline Central Denmark Region & 499 & $(18.4)$ \\
\hline North Denmark Region & 878 & $(32.4)$ \\
\hline Female, n (\%) & 1.798 & $(66.4)$ \\
\hline Age, mean (SD) & 48.3 & $(15.1)$ \\
\hline \multicolumn{3}{|l|}{ Education, n (\%) } \\
\hline Unskilled & 392 & $(14.8)$ \\
\hline Lower level (<3 years) & 596 & $(22.5)$ \\
\hline Vocational and training & 426 & $(16.1)$ \\
\hline Medium level (3-4 years) & 802 & (30.3) \\
\hline Higher level (>4 years) & 315 & (11.9) \\
\hline Other & 118 & $(4.5)$ \\
\hline \multicolumn{3}{|l|}{ Health-related benefits, n (\%) } \\
\hline None & 1.776 & $(65.6)$ \\
\hline Temporary & 245 & $(9.1)$ \\
\hline Permanent & 181 & $(6.7)$ \\
\hline Retired & 504 & (18.6) \\
\hline Private health insurance, $\mathrm{n}(\%)$ & 798 & $(30.1)$ \\
\hline Compensation claim (litigation), n (\%) & 139 & $(5.2)$ \\
\hline \multicolumn{3}{|l|}{ Pain and Function } \\
\hline \multicolumn{3}{|l|}{ Pain duration } \\
\hline$<1$ month & 640 & $(24.2)$ \\
\hline $1-3$ months & 739 & $(27.9)$ \\
\hline 4-12 months & 505 & $(19.1)$ \\
\hline$>12$ months & 766 & $(28.9)$ \\
\hline Pain score $0-10$, mean (SD) & 6.5 & $(2.3)$ \\
\hline Number of pain sites $0-9$, mean (SD) & 2.8 & $(1.7)$ \\
\hline Pain during activity score $0-100$, mean (SD) & 32.7 & $(20.6)$ \\
\hline Disability score 0-100, mean (SD) & 26.2 & $(20.0)$ \\
\hline \multicolumn{3}{|l|}{ Frequency of pain, n (\%) } \\
\hline Constant & 979 & $(36.9)$ \\
\hline Daily basis & 1,341 & $(50.6)$ \\
\hline 2-6 times a week & 212 & $(8.0)$ \\
\hline $1-4$ times a month & 76 & $(2.9)$ \\
\hline Less often & 42 & $(1.6)$ \\
\hline \multicolumn{3}{|l|}{ Taking pain medication, $\mathrm{n}(\%)$} \\
\hline Several times a day & 818 & (30.9) \\
\hline Once a day & 243 & $(9.2)$ \\
\hline 2-6 times a week & 518 & (19.5) \\
\hline 1-4 times a month & 383 & $(14.5)$ \\
\hline Less often & 226 & $(8.5)$ \\
\hline Never & 462 & $(17.4)$ \\
\hline
\end{tabular}

Table 1 Baseline characteristics $(n=2,706)$ (Continued)

Co morbidity, $\mathrm{n}(\%)$

\begin{tabular}{lll}
1 & 591 & (22.3) \\
2 or more & 224 & $(8.5)$ \\
Previous episode, $\mathrm{n}(\%)$ & 1.357 & $(50.7)$ \\
Sychological factors & & \\
Fear avoidance 0-30, mean (SD) & 15.8 & $(8.4)$ \\
Coping skills 0-10, mean (SD) & 5.4 & $(2.8)$ \\
Sleep score 0-100, mean (SD) & 35.3 & $(29.0)$ \\
Mental health score 0-100, mean (SD) & 75.0 & $(17.6)$ \\
Health behaviour & & \\
Smoker, $\mathrm{n}$ (\%) & 532 & $(19.7)$ \\
Body Mass Index, mean (SD) & 26.1 & (4.7) \\
Physical activity $\geq 30$ min.0-7 days, mean (SD) & 4.1 & $(2.5)$ \\
\hline
\end{tabular}

Abbreviation: $S D$ standard deviation

relevant improvements were observed across outcomes; however, in keeping with the recurrent and fluctuating nature of many musculoskeletal conditions, only $52 \%$ of patients rated their symptoms as acceptable at 6 months. A higher probability of satisfactory outcome was associated with geographic region, being retired, no compensation claim, less frequent pain, shorter duration of pain, lower levels of disability, lower levels of fear avoidance, better mental health and being a non-smoker. Primary pain site diagnosis had little impact on the strength of these associations and did not add any significant predictive ability.

\section{Methodological considerations}

Our study included a large consecutive cohort of patients who were recruited from many physiotherapy practices and therefore the results are likely to reflect primary care musculoskeletal problems as they present

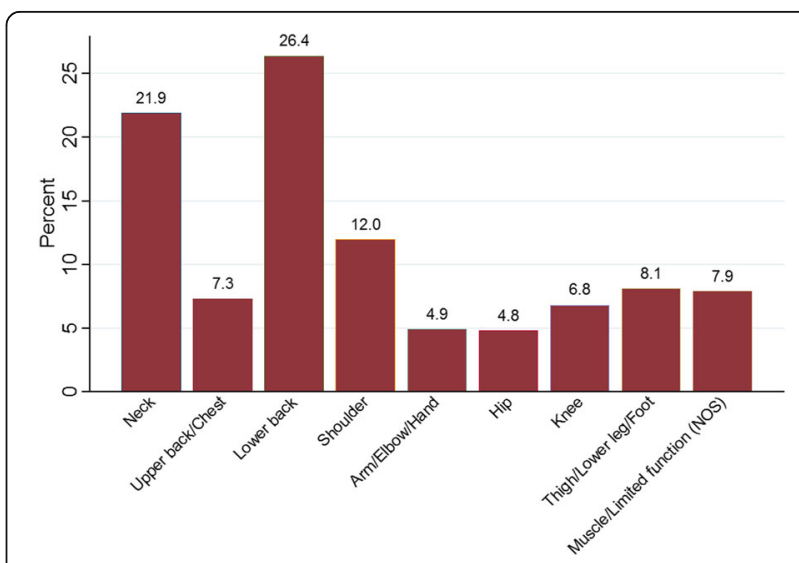

Fig. 2 Primary pain diagnosis (ICPC-2 classification) $(n=2669) *{ }^{*}$ No pain diagnosis recorded in 37 patients. Abbreviation: NOS $=$ Not Otherwise Specified 
Table 2 Results of multivariable analysis with rating symptoms acceptable as outcome without (Model 1) and with inclusion of primary pain diagnosis (Model 2)

\begin{tabular}{lllll}
\hline & \multicolumn{2}{l}{ Model 1 } & \multicolumn{2}{l}{ Model 2} \\
\hline Variables & OR & $95 \% \mathrm{Cl}$ & OR & $95 \% \mathrm{Cl}$ \\
Socio-demographic & & & & \\
Geographical Regions $^{\mathrm{a}}$ & & & & \\
$\quad$ Capital Region of Denmark & 1.00 & & 1.00 & \\
$\quad$ Region of Southern Denmark & 1.14 & $0.92-1.41$ & 1.16 & $0.93-1.43$ \\
$\quad$ Central Denmark Region & 1.25 & $1.00-1.57$ & 1.29 & $1.02-1.62$ \\
$\quad$ North Denmark Region & 1.41 & $1.15-1.74$ & 1.44 & $1.16-1.78$ \\
Health-related income support & \\
$\quad$ & & & & \\
$\quad$ None & 1.00 & & 1.00 & \\
$\quad$ Temporary & 0.73 & $0.54-1.00$ & 0.77 & $0.56-1.05$ \\
$\quad$ Permanent & 0.77 & $0.54-1.10$ & 0.78 & $0.55-1.11$ \\
$\quad$ Retired & 1.18 & $0.97-1.43$ & 1.22 & $1.01-1.48$ \\
Compensation claim & & & & \\
$\quad$ No & 1.00 & & 1.00 & \\
$\quad$ Yes & 0.59 & $0.40-0.86$ & 0.58 & $0.40-0.85$
\end{tabular}

Pain and Function

Pain duration

$<1$ month $\quad 1.00$

$1-3$ months $\quad 0.59$

4-12 months $\quad 0.46$

$>12$ months $\quad 0.49$

Disability score $0-100^{\mathrm{b}} \quad 0.99$

Frequency of pain (Constant or daily)

No

Yes

Psychological factors

Fear avoidance $0-30^{\mathrm{b}}$

Mental health score $0-100^{\mathrm{b}}$

Health behaviour

Smoker

\begin{tabular}{|c|c|c|c|}
\hline No & 1.00 & & \\
\hline Yes & $0.87 \quad 0.79-0.96$ & 0.87 & $0.78-0.96$ \\
\hline \multicolumn{4}{|l|}{ Primary pain diagnosis } \\
\hline Muscle/Limited function NOS & & 1.00 & \\
\hline Neck & & 1.30 & $0.94-1.80$ \\
\hline Upper back/Chest & & 0.90 & $0.60-1.34$ \\
\hline Low back & & 1.00 & $0.73-1.37$ \\
\hline Shoulder & & 0.95 & $0.66-1.35$ \\
\hline Arm/Elbow/Hand & & 1.04 & $0.68-1.60$ \\
\hline Hip & & 1.09 & $0.71-1.67$ \\
\hline Knee & & 0.80 & $0.53-1.21$ \\
\hline Thigh/Lower leg/Foot & & 0.85 & $0.58-1.25$ \\
\hline
\end{tabular}

to Danish physiotherapists. Information from several data sources was combined (i.e. clinical data, questionnaire data and registry data) allowing the inclusion of a broad variety of variables to describe the clinical course and to identify predictors of outcome.

A limitation of this study is that $33 \%$ of the patients invited to participate declined the offer and another $12 \%$ had to be excluded due to incomplete data and for other reasons. This modest participation rate may have affected the generalisability of our findings, although it also reflects the general difficulty of recruiting consecutive cohorts of patients from routine clinical practice. Such non-participation rates are common in large population studies and there is evidence from other Danish studies that the estimated associations between variables may not necessarily be biased by non-participation $[49,50]$. In our case, missing values in baseline variables were few, but response rates at the three follow-up points were only moderate and there were identified differences between responders and non-responders. Although we conducted analyses using all the available data by use of longitudinal regression modelling, which is robust to missing data $[51,52]$, this cannot preclude a selection bias. Some would argue that when assessing prognosis, a 12-month follow up would be a preferable endpoint. However, the 6-month endpoint in the current study was chosen as little additional change has been shown to occur beyond this point in common musculoskeletal conditions, such as low back pain [53]. We used an established diagnostic classification system and validated questionnaires; we also chose a main outcome measure that is not commonly used in prognostic studies, albeit that it might provide a more meaningful outcome in patients with musculoskeletal disorders. The concept underpinning the PASS is the level of symptoms beyond which patients consider themselves well (in a satisfactory state) rather than having just experienced a change in symptoms. As this is a state of well-being characterised by at least a state of partial remission, from a patient perspective, it can be considered a highly relevant treatment goal $[43,45,54]$. Understanding factors that are related to achieving and maintaining such a state would provide useful information for daily clinical practice. That significantly better pain and disability scores were observed for patients who perceived their symptoms as acceptable at three follow up points than those patients who did not perceive their symptoms as acceptable, adds to the concurrent validity of this outcome measure.

It could also be argued that diagnostic pain site labelling according to the ICPC-2 system is too broad for musculoskeletal pain conditions, but repeating the analyses after reclassifying neck and low back patients into those with or without radiating pain did not change our results. While no consensus exists on the best method to build models using candidate predictors, some have argued that backward elimination method that we used is the preferred method [48]. Also, while the choice of significance level can effect the number of variables selected, a sensitivity analysis demonstrated that, if the significance level were changed, 
two additional predictors would have been included (gender and sleep problems) but this would not have substantially altered the results and conclusion of the study. Furthermore, although a large number of candidate variables were included in our study, the achievement of a satisfactory outcome could also be related to other factors that we did not measure, such as patients' beliefs and expectations of treatment.

\section{Clinical course}

The distribution of gender, age, duration of symptoms and primary pain site diagnoses in our study, is similar to that found in a previous Danish study of patients referred to physiotherapy [5], as well as cohorts of musculoskeletal physiotherapy patients from other countries [55]. The overall improvement on the outcomes of pain intensity, disability and sick leave (temporary health-related income support) was similar in size to those previously observed in musculoskeletal conditions such as low back pain [53] and exceeded a common threshold of clinically relevant important change (i.e. > 30\% improvement from baseline) [56]. However, the design of the current study does not allow any judgments to be made about the effectiveness of physiotherapy treatment, as considerable improvement in musculoskeletal pain has been observed without any treatment [57]. Only half of the patients rated their symptoms as acceptable at 6 months, which is in accordance with previous findings in general practice - reporting pain and disability to persist in up to $60 \%$ in cohorts of primary care patients with low back, shoulder, and upper extremity pain [58-60]. Thus, despite the physiotherapy treatment in our study, which almost always included active treatment strategies, this relatively moderate success rate suggests either that there is potential for improvement in treatment and/or that musculoskeletal pain conditions are inherently difficult to treat. Contemporary evidence would suggest that shifting from a more traditional physiotherapy pain-centred treatment paradigm to a more function-centred treatment approach focusing on improving function, teaching patients to understand and cope with the episodic nature and fluctuating pattern of musculoskeletal pain, may be key elements to improving the perception of a satisfactory outcome in musculoskeletal physiotherapy patients.

\section{Predictors of satisfactory outcome}

In our study, a number of predictors associated with satisfactory outcome were identified from diverse health domains. Duration of symptoms, disability levels and psychological factors have consistently been found to be associated with subsequent outcomes in multiple prognostic studies in primary care $[8,9,19]$. We found symptoms of shorter duration and less frequent pain to be also associated with a higher probability of satisfactory outcome, consistent with previous studies of different outcomes.
The concept of categorising musculoskeletal pain as acute, subacute or chronic by focusing on symptom duration has more recently been challenged by longitudinal studies of trajectories (patterns of change in pain over time) in low back pain [61]. These studies suggest that most people with low back pain have trajectories of either episodic, fluctuating or persistent pain, rather than one well-defined episode. Whether these trajectories can be identified across musculoskeletal pain conditions and thereby improve the prediction of outcome needs further investigation, but approaches that generalise across musculoskeletal conditions would simplify clinical practice. Similar to our findings, being a non-smoker has previously been shown to be associated with a better prognosis among primary care patients seeking care for upper extremity pain [62]. Whereas for other pain sites, similar results have not been reported, partly because smoking has less frequently been included in prognostic studies of musculoskeletal pain [8-12, 19, 63].

Socio-demographic variables that predicted outcome, included compensation claim, geographic region and healthrelated income support. Having an ongoing compensation claim can be stressful and is a predictor of outcome in secondary care neck and back patients $[64,65]$. Although, this involves a very small group among musculoskeletal physiotherapy patients, similar mechanisms could be influential in primary care. The findings that patients were more likely to perceive their symptoms as acceptable in the central and northern geographic regions of Denmark and when retired from the labour market, suggests the prognostic implications of within-country cultural differences and of having no work life demands. Differences in prognostic influences between countries have previously been reported in cohorts of chiropractic spinal pain patients [66], but as far as we are aware, these within-country geographical differences in Denmark among musculoskeletal physiotherapy patients are a novel finding. Whether the higher probability of achieving a satisfactory outcome in more sparsely populated areas (North Region), when compared to densely populated areas (Capital Region), is related to differences in accessibility of physiotherapy services, treatment beliefs, expectations or other factors needs further investigation. Furthermore, the strength of the observed associations was mostly modest and several of the strongest associations were for predictors which are constructs that are not easily modifiable (e.g. duration of symptoms, compensation claims and geographical differences). This currently presents a challenge for clinical practice and prognostic research. Therefore, understanding what potentially modifiable underlying factors may influence such constructs may be an important future research aim [13].

\section{Influence of primary pain site diagnosis}

Primary pain site diagnosis had little impact on the prediction of outcome. The prognosis of patients did not differ 
across the primary pain site diagnosis from that of patients who were classified with non-specific muscular symptoms and limited function. These results are supported by those from cohort studies in the USA, showing anatomical pain sites did not influence the predictive value of psychological factors, such as fear avoidance beliefs and depressive symptoms, in patients seeking physiotherapy treatment for musculoskeletal pain $[67,68]$. Traditionally, clinical practice prognosis and treatment has been based on medical diagnoses but the central role of diagnosis has recently been challenged in conditions such as musculoskeletal pain, where other factors have been shown to be more influential on the outcome [6]. In patients with musculoskeletal pain, many symptoms (such as pain, stiffness, and pain interference with work and daily routine) are common regardless of where the primary pain site is. In musculoskeletal pain conditions, prognosis seems to be less about 'where you have it' and more about 'how much pain and disability you have and your pain perceptions'. Diagnosis is likely to be most relevant in conditions where there is an available treatment that effectively targets the causal pathways of a specific disease. In health conditions such as musculoskeletal pain, physiotherapy treatment strategies largely depend on the same strategies, such as advice, reassurance, manual therapy and exercise, and therefore are probably better understood and managed within a prognostic framework.

\section{Conclusion}

Among Danish musculoskeletal physiotherapy patients, only one in two perceived their symptoms as acceptable at 6 months, despite the average improvement being above the threshold for clinically important change. A number of predictors of satisfactory outcome were identified, which appear to be prognostic regardless of primary pain site diagnosis and which may have a role in generic prediction models for physiotherapy patients with musculoskeletal pain. While clearly there is a role for studies of single-site musculoskeletal pain, our results also support the need for more research that offers insights into the drivers of recovery regardless of pain site and provides generic tools to assist the management of musculoskeletal pain, whether it be single-site or multi-site.

\section{Additional file}

Additional file 1: Cross-cultural adaptation and validation of the Danish version of the Standard Evaluation Questionnaire (SEQ) modules. (DOCX $251 \mathrm{~kb}$ )

\section{Abbreviations}

GEE: Generalised Estimating Equation; ICPC-2: International Classification for Primary Care $2^{\text {nd }}$ edition; $\mathrm{MH}-5$ : Mental Health Scale - Five;

MSPQ: Musculoskeletal Pain Screening Questionnaire; NOS: Not Otherwise Specified; PASS: Patient Acceptable Symptom State; SEQ: Standard Evaluation Questionnaire (SEQ)

\section{Acknowledgments}

The authors wish to thank the participating physiotherapists and their secretarial staff for their valuable assistance in data collection.

\section{Funding}

The study was supported by the Practice Research Foundation of Danish Physiotherapists.

\section{Availability of data and materials}

The study datasets from which we have reported findings in this paper cannot be accessed by other researchers according to Danish regulations. Researchers who are interested to use the same data need to apply for data access directly to The Danish Data Protection Agency (https://www.datatilsynet.dk/forside/). Interested researchers may contact the corresponding author of this article for further guidance on this procedure.

\section{Authors' contributions}

NBA and DHC planned and designed the study. DHC performed the statistical analyses. NBA, DHC and PK drafted the manuscript. All authors contributed to interpretation of data and critical revision of the manuscript. All authors read and approved the final manuscript.

\section{Competing interests}

We declare no competing interests.

Consent for publication

Not applicable.

Ethics approval and consent to participate

All participants signed written informed consent forms and the study was approved by the Danish Data Protection Agency (No. 2007-58-0010). As treatment was not affected by participation in the study, under Danish law, this study did not need ethics approval (Act on Research Ethics Review of Health Research Projects, October 2013) [20].

\section{Publisher's Note}

Springer Nature remains neutral with regard to jurisdictional claims in published maps and institutional affiliations.

\section{Author details}

${ }^{1}$ Primary Health Care and Quality Improvement, Viborg, Central Denmark Region, Denmark. ${ }^{2}$ School of Physiotherapy and Exercise Science, Curtin University, Bentley, WA, Australia. ${ }^{3}$ Department of Sports Science and Clinical Biomechanics, University of Southern Denmark, Odense, Denmark. ${ }^{4}$ Department of Clinical Medicine, HEALTH, Aarhus University, Aarhus, Denmark. ${ }^{5}$ Department of Occupational Medicine, Regional Hospital West Jutland-University Research Clinic, Herning, Denmark.

Received: 30 September 2016 Accepted: 14 March 2017

Published online: 29 March 2017

\section{References}

1. Briggs AM, Cross MJ, Hoy DG, Sanchez-Riera L, Blyth FM, Woolf AD, March L. Musculoskeletal Health Conditions Represent a Global Threat to Healthy Aging: A Report for the 2015 World Health Organization World Report on Ageing and Health. Gerontologist. 2016;56 Suppl 2:S243-55.

2. Murray CJ, Vos T, Lozano R, Naghavi M, Flaxman AD, Michaud C, Ezzati M, Shibuya K, Salomon JA, Abdalla S, Aboyans V, Abraham J, Ackerman I, Aggarwal R, Ahn SY, Ali MK, Alvarado M, Anderson HR, Anderson LM, Andrews KG, Atkinson C, Baddour LM, Bahalim AN, Barker-Collo S, Barrero LH, Bartels DH, Basanez MG, Baxter A, Bell ML, Benjamin EJ, Bennett D, Bernabe E, Bhalla K, Bhandari B, Bikbov B, Bin Abdulhak A, Birbeck G, Black JA, Blencowe H, Blore JD, Blyth F, Bolliger I, Bonaventure $A$, Boufous $S$, Bourne R, Boussinesq $M$, Braithwaite $T$, Brayne C, Bridgett L, Brooker S, Brooks P, Brugha TS, Bryan-Hancock C, Bucello C, Buchbinder R, Buckle G, Budke CM, Burch M, Burney P, Burstein R, Calabria B, Campbell B, Canter CE, Carabin H, Carapetis J, Carmona L, Cella C, Charlson F, Chen H, Cheng AT, Chou D, Chugh SS, Coffeng LE, Colan SD, Colquhoun S, Colson KE, Condon J, Connor MD, Cooper LT, Corriere M, Cortinovis M, de Vaccaro KC, Couser W, Cowie BC, Criqui MH, Cross M, Dabhadkar KC, Dahiya M, Dahodwala N, 
Damsere-Derry J, Danaei G, Davis A, De Leo D, Degenhardt L, Dellavalle R, Delossantos A, Denenberg J, Derrett S, Des Jarlais DC, Dharmaratne SD, Dherani M, Diaz-Torne C, Dolk H, Dorsey ER, Driscoll T, Duber H, Ebel B, Edmond K, Elbaz A, Ali SE, Erskine H, Erwin PJ, Espindola P, Ewoigbokhan SE, Farzadfar F, Feigin V, Felson DT, Ferrari A, Ferri CP, Fevre EM, Finucane MM, Flaxman S, Flood L, Foreman K, Forouzanfar MH, Fowkes FG, Fransen M, Freeman MK, Gabbe BJ, Gabriel SE, Gakidou E, Ganatra HA, Garcia B, Gaspari F, Gillum RF, Gmel G, Gonzalez-Medina D, Gosselin R, Grainger R, Grant B, Groeger J, Guillemin F, Gunnell D, Gupta R, Haagsma J, Hagan H, Halasa YA, Hall W, Haring D, Haro JM, Harrison JE, Havmoeller R, Hay RJ, Higashi H, Hill C, Hoen B, Hoffman H, Hotez PJ, Hoy D, Huang JJ, Ibeanusi SE, Jacobsen $\mathrm{KH}$, James $\mathrm{SL}$, Jarvis $\mathrm{D}$, Jasrasaria $\mathrm{R}$, Jayaraman $\mathrm{S}$, Johns $\mathrm{N}$, Jonas JB, Karthikeyan G, Kassebaum N, Kawakami N, Keren A, Khoo JP, King $\mathrm{CH}$, Knowlton LM, Kobusingye $\mathrm{O}$, Koranteng A, Krishnamurthi $\mathrm{R}$, Laden F, Lalloo R, Laslett LL, Lathlean T, Leasher JL, Lee YY, Leigh J, Levinson D, Lim SS, Limb E, Lin JK, Lipnick M, Lipshultz SE, Liu W, Loane M, Ohno SL, Lyons R, Mabweijano J, Maclntyre MF, Malekzadeh R, Mallinger L, Manivannan S, Marcenes W, March L, Margolis DJ, Marks GB, Marks R, Matsumori A, Matzopoulos R, Mayosi BM, McAnulty JH, McDermott MM, McGill N, McGrath J, Medina-Mora ME, Meltzer M, Mensah GA, Merriman TR, Meyer AC, Miglioli V, Miller M, Miller TR, Mitchell PB, Mock C, Mocumbi AO, Moffitt TE, Mokdad AA, Monasta L, Montico M, Moradi-Lakeh M, Moran A, Morawska L, Mori R, Murdoch ME, Mwaniki MK, Naidoo K, Nair MN, Naldi L, Narayan KM, Nelson PK, Nelson RG, Nevitt MC, Newton CR, Nolte $S$, Norman $P$, Norman R, O'Donnell M, O'Hanlon S, Olives C, Omer SB, Ortblad K, Osborne R, Ozgediz D, Page A, Pahari B, Pandian JD, Rivero AP, Patten SB, Pearce N, Padilla RP, Perez-Ruiz F, Perico N, Pesudovs K, Phillips D, Phillips MR, Pierce K, Pion S, Polanczyk GV, Polinder S, Pope 3rd CA, Popova S, Porrini E, Pourmalek F, Prince M, Pullan RL, Ramaiah KD, Ranganathan D, Razavi H, Regan M, Rehm JT, Rein DB, Remuzzi G, Richardson K, Rivara FP, Roberts T, Robinson C, De Leon FR, Ronfani L, Room R, Rosenfeld LC, Rushton L, Sacco RL, Saha S, Sampson U, Sanchez-Riera L, Sanman E, Schwebel DC, Scott JG, Segui-Gomez M, Shahraz S, Shepard DS, Shin H, Shivakoti R, Singh D, Singh GM, Singh JA, Singleton J, Sleet DA, Sliwa K, Smith E, Smith JL, Stapelberg NJ, Steer A, Steiner T, Stolk WA, Stovner U, Sudfeld C, Syed S, Tamburlini G, Tavakkoli M, Taylor HR, Taylor JA, Taylor WJ, Thomas B, Thomson WM, Thurston GD, Tleyjeh IM, Tonelli M, Towbin JA, Truelsen T, Tsilimbaris MK, Ubeda C, Undurraga EA, van der Werf MJ, van Os J, Vavilala MS, Venketasubramanian N, Wang M, Wang W, Watt K, Weatherall DJ, Weinstock MA, Weintraub R, Weisskopf MG, Weissman MM, White RA, Whiteford H, Wiebe N, Wiersma ST, Wilkinson JD, Williams HC, Williams SR, Witt E, Wolfe F, Woolf AD, Wulf S, Yeh PH, Zaidi AK, Zheng ZI, Zonies D, Lopez AD, AlMazroa MA, Memish ZA. Disability-adjusted life years (DALYS) for 291 diseases and injuries in 21 regions, 1990-2010: a systematic analysis for the Global Burden of Disease Study 2010. Lancet. 2012;380(9859):2197-223.

3. Christensen Al, Ekholm O, Davidsen M, Juel K. Sundhed og sygelighed i Danmark 2010 \& udviklingen siden 1987 [Health and morbidity in Denmark 2010 and developments since 1987]. Copenhagen: Statens Institut For Folkesundhed; 2012

4. Mose S, Christiansen DH, Jensen JC, Andersen JH. Widespread pain - do pain intensity and care-seeking influence sickness absence? - A populationbased cohort study. BMC Musculoskelet Disord. 2016;17(1):197. -016-1056-1.

5. Jorgensen $C K$, Fink $P$, Olesen $F$. Patients in general practice in Denmark referred to physiotherapists: a description of patient characteristics based on general health status, diagnoses, and sociodemographic characteristics. Phys Ther. 2001; 81(3):915-23.

6. Croft P, Altman DG, Deeks JJ, Dunn KM, Hay AD, Hemingway H, LeResche L, Peat G, Perel P, Petersen SE, Riley RD, Roberts I, Sharpe M, Stevens RJ, Van Der Windt DA, Von Korff M, Timmis A. The science of clinical practice: disease diagnosis or patient prognosis? Evidence about "what is likely to happen" should shape clinical practice. BMC Med. 2015;13:20.

7. Foster NE, Dziedzic KS, Van DW, Fritz JM, Hay EM. Research priorities for nonpharmacological therapies for common musculoskeletal problems: nationally and internationally agreed recommendations. BMC Musculoskeletal Disorders. 2009;10:3.

8. Hayden JA, Chou R, Hogg-Johnson S, Bombardier C. Systematic reviews of low back pain prognosis had variable methods and results: guidance for future prognosis reviews. J Clin Epidemiol. 2009:62(8):781-796.e1.

9. Bruls VE, Bastiaenen CH, de Bie RA. Prognostic factors of complaints of arm, neck, and/or shoulder: a systematic review of prospective cohort studies. Pain. 2015;156(5):765-88.
10. Chester R, Shepstone L, Daniell H, Sweeting D, Lewis J, Jerosch-Herold C. Predicting response to physiotherapy treatment for musculoskeletal shoulder pain: a systematic review. BMC Musculoskelet Disord. 2013;14:203.

11. Richmond SA, Fukuchi RK, Ezzat A, Schneider K, Schneider G, Emery CA. Are joint injury, sport activity, physical activity, obesity, or occupational activities predictors for osteoarthritis? A systematic review. J Orthop Sports Phys Ther. 2013;43(8):515-B19.

12. Bastick AN, Runhaar J, Belo JN, Bierma-Zeinstra SM. Prognostic factors for progression of clinical osteoarthritis of the knee: a systematic review of observational studies. Arthritis Res Ther. 2015;17:152.

13. Hayden JA, Cote P, Steenstra IA, Bombardier C. QUIPS-LBP Working Group. Identifying phases of investigation helps planning, appraising, and applying the results of explanatory prognosis studies. J Clin Epidemiol. 2008;61(6):552-60.

14. Pincus T, Burton AK, Vogel S, Field AP. A systematic review of psychological factors as predictors of chronicity/disability in prospective cohorts of low back pain. Spine. 2002;27(5):E109-20.

15. Leboeuf-Yde C, Kruger Jensen R, Wedderkopp N. Persistence of pain in patients with chronic low back pain reported via weekly automated text messages over one year. BMC Musculoskelet Disord. 2015;16:299.

16. Bergbom S, Boersma K, Overmeer T, Linton SJ. Relationship among pain catastrophizing, depressed mood, and outcomes across physical therapy treatments. Phys Ther. 2011;91(5):754-64.

17. Tubach F, Wells GA, Ravaud P, Dougados M. Minimal clinically important difference, low disease activity state, and patient acceptable symptom state: methodological issues. J Rheumatol. 2005;32(10):2025-9.

18. Tubach F, Ravaud P, Beaton D, Boers M, Bombardier C, Felson DT, van der Heijde D, Wells G, Dougados M. Minimal clinically important improvement and patient acceptable symptom state for subjective outcome measures in rheumatic disorders. J Rheumatol. 2007;34(5):1188-93.

19. Mallen CD, Peat G, Thomas E, Dunn KM, Croft PR. Prognostic factors for musculoskeletal pain in primary care: a systematic review. Br J Gen Pract. 2007:57(541):655-61.

20. Danish National Committee on Biomedical Research Ethics. Act on research ethics review of health research projects. 2013. http://www.nvk.dk/english/ act-on-research. Accessed 20 Mar 2017.

21. Muller U, Tanzler K, Burger A, Staub L, Tamcan O, Roeder C, Juni P, Trelle S. A pain assessment scale for population-based studies: development and validation of the pain module of the Standard Evaluation Questionnaire. Pain. 2008;136(1-2):62-74.

22. Rieger B, Tamcan O, Dietrich D, Muller U. Ageing challenges the results of any outcome study: how to address the effects of ageing on activities of daily living. J Int Med Res. 2012;40(2):726-33.

23. Aghayev E, Sprott $H$, Bohler D, Roder C, Muller U. Sleep quality, the neglected outcome variable in clinical studies focusing on locomotor system; a construct validation study. BMC Musculoskelet Disord. 2010;11:224.

24. Linton SJ, Hallden K. Can we screen for problematic back pain? A screening questionnaire for predicting outcome in acute and subacute back pain. Clin J Pain. 1998;14(3):209-15.

25. Linton SJ, Boersma K. Early identification of patients at risk of developing a persistent back problem: the predictive validity of the Orebro Musculoskeletal Pain Questionnaire. Clin J Pain. 2003;19(2):80-6.

26. McHorney CA, Ware Jr JE. Construction and validation of an alternate form general mental health scale for the Medical Outcomes Study Short-Form 36-Item Health Survey. Med Care. 1995;33(1):15-28.

27. Wild D, Grove A, Martin M, Eremenco S, McElroy S, Verjee-Lorenz A, Erikson P. Principles of Good Practice for the Translation and Cultural Adaptation Process for Patient-Reported Outcomes (PRO) Measures: report of the ISPOR Task Force for Translation and Cultural Adaptation. Value Health. 2005;8(2):94-104.

28. Terwee CB, Bot SD, de Boer MR. van dW, Knol DL, Dekker J, Bouter LM, de Vet HC. Quality criteria were proposed for measurement properties of health status questionnaires. J Clin Epidemiol. 2007;60(1):34-42.

29. Mokkink LB, Terwee CB, Knol DL, Stratford PW, Alonso J, Patrick DL, Bouter LM, de Vet HC. The COSMIN checklist for evaluating the methodological quality of studies on measurement properties: a clarification of its content. BMC Med Res Methodol. 2010;10:22.

30. Herup A, Merser S, Boeckstyns M. Validation of questionnaire for conditions of the upper extremity. Ugeskr Laeger. 2010;172(48):3333-6.

31. Hudak PL, Amadio PC, Bombardier C. Development of an upper extremity outcome measure: the DASH (disabilities of the arm, shoulder and hand) [corrected]. The Upper Extremity Collaborative Group (UECG). Am J Ind Med. 1996;29(6):602-8. 
32. Fairbank JC, Couper J, Davies JB, O'Brien JP. The Oswestry low back pain disability questionnaire. Physiotherapy. 1980;66(8):271-3.

33. Lauridsen HH, Hartvigsen J, Manniche C, Korsholm L, Grunnet-Nilsson N. Danish version of the Oswestry Disability Index for patients with low back pain. Part 1: Cross-cultural adaptation, reliability and validity in two different populations. Eur Spine J. 2006;15(11):1705-16.

34. Bremander AB, Petersson IF, Roos EM. Validation of the Rheumatoid and Arthritis Outcome Score (RAOS) for the lower extremity. Health Qual Life Outcomes. 2003:1:55.

35. Hjollund NH, Larsen FB, Andersen JH. Register-based follow-up of social benefits and other transfer payments: accuracy and degree of completeness in a Danish interdepartmental administrative database compared with a population-based survey. Scand J Public Health. 2007:35(5):497-502.

36. Andersen JS, De Fine ON, Krasnik A. The Danish National Health Service Register. Scand J Public Health. 2011;39(7 suppl):34-7.

37. International Classification of Primary Care, Second edition (ICPC-2). http:// www.who.int/classifications/icd/adaptations/icpc2/en/. Accessed 20 Mar 2017.

38. Nielsen MN, Aaen-Larsen B, Vedsted P, Nielsen CV, Hjollund NH. Diagnosis coding of the musculoskeletal system in general practice. Ugeskr Laeger. 2008;170(37):2881-4.

39. Kent PM, Keating JL. Can we predict poor recovery from recent-onset nonspecific low back pain? A systematic review. Man Ther. 2008;13(1):12-28.

40. Jensen LD, Frost P, Schiottz-Christensen B, Maribo T, Christensen MV Svendsen SW. Predictors of vocational prognosis after herniated lumbar disc: a two-year follow-up study of 2039 patients diagnosed at hospital. Spine (Phila Pa 1976). 2011;36(12):E791-7.

41. Biering K, Nielsen TT, Rasmussen K, Niemann T, Hjollund NH. Return to work after percutaneous coronary intervention: the predictive value of self-reported health compared to clinical measures. PLoS One. 2012;7(11):e49268.

42. Boersma K, Linton SJ. Screening to identify patients at risk: profiles of psychological risk factors for early intervention. Clin J Pain. 2005;21(1):38-43.

43. Tubach F, Ravaud P, Baron G, Falissard B, Logeart I, Bellamy N, Bombardier C, Felson D, Hochberg M, van der Heijde D, Dougados M. Evaluation of clinically relevant states in patient reported outcomes in knee and hip osteoarthritis: the patient acceptable symptom state. Ann Rheum Dis. 2005;64(1):34-7.

44. Kvien TK, Heiberg T, Hagen KB. Minimal clinically important improvement/ difference (MCII/MCID) and patient acceptable symptom state (PASS): what do these concepts mean? Ann Rheum Dis. 2007;66 Suppl 3:iii40-1.

45. Tubach F, Pham T, Skomsvoll JF, Mikkelsen K, Bjorneboe O, Ravaud P, Dougados M, Kvien TK. Stability of the patient acceptable symptomatic state over time in outcome criteria in ankylosing spondylitis. Arthritis Rheum. 2006:55(6):960-3.

46. Twisk J. Applied Longitudinal Data Analysis for Epidemiology: A Practical Guide. 2013.

47. Kirkwood B, Sterne Jonthan AC. Essential medical statistics: Malden. MA Blackwell Science Ltd; 2003.

48. Royston P, Moons KG, Altman DG, Vergouwe Y. Prognosis and prognostic research: Developing a prognostic model. BMJ. 2009;338:b604.

49. Nohr EA, Frydenberg M, Henriksen TB, Olsen J. Does low participation in cohort studies induce bias? Epidemiology. 2006;17(4):413-8.

50. Winding TN, Andersen $\mathrm{JH}$, Labriola M, Nohr EA. Initial non-participation and loss to follow-up in a Danish youth cohort: implications for relative risk estimates. J Epidemiol Community Health. 2014:68(2):137-44.

51. Kenward MG, Carpenter J. Multiple imputation: current perspectives. Stat Methods Med Res. 2007;16(3):199-218.

52. Twisk J, de Boer M, de Vente W, Heymans M. Multiple imputation of missing values was not necessary before performing a longitudinal mixedmodel analysis. J Clin Epidemiol. 2013;66(9):1022-8.

53. Artus $M$, van der Windt $D$, Jordan KP, Croft PR. The clinical course of low back pain: a meta-analysis comparing outcomes in randomised clinical trials (RCTs) and observational studies. BMC Musculoskelet Disord. 2014;15:68.

54. Tubach F, Dougados M, Falissard B, Baron G, Logeart I, Ravaud P. Feeling good rather than feeling better matters more to patients. Arthritis Rheum. 2006:55(4):526-30

55. Swinkels IC, Hart DL, Deutscher D, van den Bosch WJ, Dekker J, de Bakker $\mathrm{DH}$, van den Ende $\mathrm{CH}$. Comparing patient characteristics and treatment processes in patients receiving physical therapy in the United States, Israel and the Netherlands: cross sectional analyses of data from three clinical databases. BMC Health Serv Res. 2008;8:163.

56. Ostelo RW, Deyo RA, Stratford P, Waddell G, Croft P, Von KM, Bouter LM, de Vet HC. Interpreting change scores for pain and functional status in low back pain: towards international consensus regarding minimal important change. Spine (Phila Pa 1976). 2008;33(1):90-4.

57. Vasseljen O, Woodhouse A, Bjørngaard JH, Leivseth L. Natural course of acute neck and low back pain in the general population: The HUNT study. PAIN. 2013;154(8):1237-44.

58. Schiottz-Christensen B, Nielsen GL, Hansen VK, Schodt T, Sorensen HT, Olesen F. Long-term prognosis of acute low back pain in patients seen in general practice: a 1-year prospective follow-up study. Fam Pract. 1999;16(3):223-32.

59. Spies-Dorgelo MN, van der Windt DA, Prins AP, Dziedzic KS, van der Horst HE. Clinical course and prognosis of hand and wrist problems in primary care. Arthritis Rheum. 2008:59(9):1349-57.

60. van der Windt DA, Koes BW, Boeke AJ, Deville W, De Jong BA, Bouter LM. Shoulder disorders in general practice: prognostic indicators of outcome. $\mathrm{Br}$ J Gen Pract. 1996;46(410):519-23.

61. Kongsted A, Kent P, Axen I, Downie AS, Dunn KM. What have we learned from ten years of trajectory research in low back pain? BMC Musculoskelet Disord. 2016;17(1):220. -016-1071-2.

62. Ryall C, Coggon D, Peveler R, Poole J, Palmer KT. A prospective cohort study of arm pain in primary care and physiotherapy-prognostic determinants. Rheumatology (Oxford). 2007;46(3):508-15.

63. Verwoerd AJ, Luijsterburg PA, Lin CW, Jacobs WC, Koes BW, Verhagen AP. Systematic review of prognostic factors predicting outcome in nonsurgically treated patients with sciatica. Eur J Pain. 2013;17(8):1126-37.

64. Kragholm K, Odgaard A, Nielsen TK, Kolstad HA, Andersen JH. Poor outcome in patients with spine-related leg or arm pain who are involved in compensation claims: a prospective study of patients in the secondary care sector: comment on the article by Rasmussen et al. Scand J Rheumatol. 2009;38(5):398-9. author reply 399.

65. Rasmussen C, Leboeuf-Yde C, Hestbaek L, Manniche C. Poor prognosis in back pain among patients who have filed financial claims - secondary publication. Ugeskr Laeger. 2009;171(19):1604-7.

66. Ailliet L, Rubinstein SM, Hoekstra T, van Tulder MW, de Vet HC. Adding Psychosocial Factors Does Not Improve Predictive Models for People With Spinal Pain Enough to Warrant Extensive Screening for Them at Baseline. Phys Ther. 2016.

67. George SZ, Stryker SE. Fear-avoidance beliefs and clinical outcomes for patients seeking outpatient physical therapy for musculoskeletal pain conditions. J Orthop Sports Phys Ther. 2011;41(4):249-59.

68. George SZ, Coronado RA, Beneciuk JM, Valencia C, Werneke MW, Hart DL. Depressive symptoms, anatomical region, and clinical outcomes for patients seeking outpatient physical therapy for musculoskeletal pain. Phys Ther. 2011:91(3):358-72

\section{Submit your next manuscript to BioMed Central and we will help you at every step:}

- We accept pre-submission inquiries

- Our selector tool helps you to find the most relevant journal

- We provide round the clock customer support

- Convenient online submission

- Thorough peer review

- Inclusion in PubMed and all major indexing services

- Maximum visibility for your research

Submit your manuscript at www.biomedcentral.com/submit
) Biomed Central 